\title{
Correlation between Th17 and nTreg cell frequencies and the stages of progression in chronic hepatitis B
}

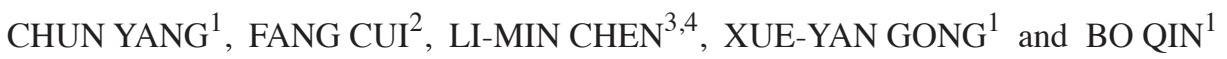 \\ ${ }^{1}$ Department of Infectious Diseases; ${ }^{2}$ Department of Clinical Laboratory, \\ The First Affiliated Hospital of Chongqing Medical University, Chongqing 400016, P.R. China; \\ ${ }^{3}$ Toronto General Research Institute, University Health Network, University of Toronto, Toronto, Ontario M5S 2J7, Canada; \\ ${ }^{4}$ Institute of Blood Transfusion, Chinese Academy of Medical Sciences and Peking Union Medical College, \\ Chengdu, Sichuan 610052, P.R. China
}

Received December 31, 2014; Accepted October 6, 2015

DOI: $10.3892 / \mathrm{mmr} .2015 .4618$

\begin{abstract}
Several studies have suggested that the balance of $\mathrm{T}$ helper 17 (Th17) and natural regulatory $\mathrm{T}$ (nTreg) cells in the Th17-mediated immune response are critical in the pathogenesis of viral hepatitis. The aim of the present study was to examine the role of circulating Th17 and nTreg cells in the disease progression of hepatitis B virus (HBV) infection. A total of 40 patients with chronic HBV (CHB), 27 patients with $\mathrm{HBV}$-associated cirrhosis, 20 patients with $\mathrm{HBV}$-associated liver failure and 20 healthy controls were enrolled in the present study. The frequencies of Th17 and nTreg cells in the peripheral blood were examined using flow cytometry. Th17-associated serum cytokine levels were measured using an enzyme-linked immunosorbent assay. The results revealed a significantly higher frequency of circulating Th17 cells in the patients with $\mathrm{CHB}$, cirrhosis and liver failure compared, with the normal controls, particularly in the patients with liver failure. The same trend was observed in the serum levels of interleukin (IL)-17. The frequency of Th17 cells and the serum levels of IL-17 were positively correlated with the levels of alanine aminotransferase and
\end{abstract}

Correspondence to: Professor Bo Qin, Department of Infectious Diseases, The First Affiliated Hospital of Chongqing Medical University, 1 Youyi Road, Yuzhong, Chongqing 400016, P.R. China E-mail: cqqinbo@126.com

Abbreviations: ALB, albumin; ALT, alanine aminotransferase; CAWC, chronic active hepatitis without cirrhosis; CD, cluster determinant; $\mathrm{CHB}$, chronic hepatitis B; ELISA, enzyme-linked immunosorbent assay; Foxp3, forkhead/winged-helix transcription factor; HBV, hepatitis B virus; HBLF, HBV-associated liver failure; IFN- $\gamma$, interferon- $\gamma$; IL, interleukin; NR, normal range; nTreg, natural regulatory T cell; PBMC, peripheral blood mononuclear cell; PCR, polymerase chain reaction; $\mathrm{PT}$, prothrombin time; TB, total bilirubin; Th17, T helper 17; TNF- $\alpha$, tumor necrosis factor $\alpha$

Key words: hepatitis B virus, hepatitis, $\mathrm{T}$ helper 17, natural regulatory $\mathrm{T}$ cell, $\mathrm{T}$ helper 17/natural regulatory $\mathrm{T}$ cell imbalance the prothrombin times. There was a significantly higher frequency of circulating nTreg cells in the patients with CHB, compared with the normal controls. The nTreg cell frequencies were significantly and positively correlated with plasma HBV DNA load, and were negatively correlated with Th17 frequencies in the cohort of patients with HBV. Taken together, the results suggested that Th17 cell-mediated inflammation is associated with progression from $\mathrm{CHB}$ to cirrhosis, and to liver failure. Peripheral Th17 cell frequency and serum levels of IL-17 may assisting in predicting the severity of liver damage and fibrosis.

\section{Introduction}

Chronic hepatitis $\mathrm{B}(\mathrm{CHB})$ is a major cause of liver cirrhosis and hepatocellular carcinoma (1). Although persistently high hepatitis B virus (HBV) loads have been correlated with disease progression, the progression itself is not caused by the HBV, but by a host immune-mediated process (2-4). An inadequate immune response leads to $\mathrm{CHB}$ infection, whereas an appropriate immune response frequently leads to viral clearance and recovery, and an excess immune response leads to liver failure (5-7). The mechanisms by which the immune responses are regulated resulting in these various outcomes remain to be elucidated.

One of the newly discovered cluster determinant (CD) $4^{+}$ $\mathrm{T}$ helper (Th) cells, Th17 cells, were first isolated from CD4 ${ }^{+}$ T cells. Th17 cells can secrete a mixture of cytokines, including interleukin (IL)-17A, IL-17F and IL-22, among which IL-17A has been characterized as a major effector cytokine $(8,9)$. IL-17A can stimulate chemotactic factors, including IL-8, monocyte chemoattractant protein-1 and growth-regulated oncogene- $\alpha$, to mobilize, recruit, and activate neutrophils and monocytes, leading to marked tissue inflammation (10). IL-17A can also stimulate a mixture of cytokines, including IL-6, prostaglandin E2 and other proinflammatory factors, including IL- $1 \beta$, tumor necrosis factor- $\alpha$ and interferon- $\gamma$, to further activate and amplify inflammatory reactions (11-13). Th17 cells can also activate natural immune cells, which express IL-17R causing an increase in liver inflammation and damage (11). Previous studies have found that Th17 cells may 
be involved in the immune responses and immunopathogenesis induced by persistent HBV infection (14-17). Th17 has been shown to be critical in autoimmune diseases and various infectious diseases (18).

Regulatory T (Treg) cells, a family of immunomodulatory cell types, are critical homeostatic regulators of immune and inflammatory responses. $\mathrm{CD} 4^{+} \mathrm{CD} 25^{+}$Tregs suppress immune responses to maintain unresponsiveness to self-antigens and prevent excessive immune responses against fatal inflammatory damage (19-21). Treg cells, which have immune incompetence and immunosuppressive characteristics, are important in CHB and chronic hepatitis C (22-24). Natural (n) Treg cells are involved in controlling immune responses, and in promoting and maintaining self-tolerance (25). They can also inhibit the proliferative responses of conventional CD4 and CD8 T cells in vitro (26).

The aim of the present study was to examine the association between circulating Th17 and nTreg cell frequencies, and the disease progression in patients infected with HBV.

\section{Patients and methods}

Patients and controls. All patients were recruited from the First Affiliated Hospital of Chongqing Medical University (Chongqing, China). The study was approved by the ethics committee of the First Affiliated Hospital of Chongqing Medical University (Chongqing, China). Written informed consent was obtained from the patients. Blood samples $(8 \mathrm{ml})$ were collected from the elbow vena mediana, from 40 patients with chronic active hepatitis, but without cirrhosis (CAWC), 27 patients with HBV-associated cirrhosis, 20 patients with HBV-associated liver failure (HBLF) and 20 age- and gender-matched healthy individuals, who were enrolled as controls. All patients were diagnosed, according to previously described criteria (27). The inclusion criteria were as follows: i) Healthy controls had no underlying disease history, were normal on physical examination and had no evidence of HBV infection within at least 6 months; ii) patients with $\mathrm{CHB}$ had been diagnosed with $\mathrm{HBV}$ for $>6$ months and presented with either persistent or recurrent elevations in serum alanine aminotransferase (ALT), or evidence of hepatitis in liver histology, but without cirrhosis; iii) patients with HBV-associated cirrhosis exhibited portal hypertension (splenomegaly and esophageal varices) on abdominal ultrasound or endoscopy, or hypersplenism in blood tests or histology, but had no evidence of liver failure; iv) patients with HBLF had serum levels of total bilirubin $>10$ times higher than then normal limit, severe coagulopathy (prothrombin activity $\leq 40 \%$ ), encephalopathy, renal insufficiency, variceal bleeding and ascites.

Patients with concurrent viral infections, human immunodeficiency virus-1 infection, alcoholic or non-alcoholic fatty liver diseases, hepatocellular carcinoma, genetic and autoimmune liver diseases were excluded. None of the patients had received antiviral or immunomodulatory therapy prior to sampling. The study protocol was approved by the Ethics Committee of the First Affiliated Hospital of Chongqing Medical University, and written informed consent was obtained from each subject. The clinical characteristics of the subjects are listed in Table I.
Flow cytometric analysis. All antibodies were purchased from BD Biosciences (San Jose, CA, USA). Peripheral blood mononuclear cells (PBMCs) were isolated from the fresh, heparinized peripheral blood samples by Ficoll-Hypaque density-gradient centrifugation (lymphocyte separation medium; Haoyang Bio-Technology Co., Ltd., Tianjin, China), according to the manufacturer's protocol. The PBMCs $\left(1 \mathrm{ml}\right.$ of $\left.2 \times 10^{6}\right)$ were treated for $5 \mathrm{~h}$ with $50 \mathrm{ng} / \mathrm{ml}$ phorbol myristate acetate (Shanghai DingGuo Biotech., Co., Ltd., Shanghai, China), $1 \mu \mathrm{g} / \mathrm{ml}$ ionomycin (Sigma-Aldrich, St. Louis, MO, USA) and $10 \mathrm{mg} / \mathrm{ml}$ brefeldin A (eBioscience, Inc., San Diego, CA, USA) in complete RPMI-1640 medium (Sigma-Aldrich) supplemented with $10 \%$ fetal bovine serum (Sigma-Aldrich). The cells were surface-stained with fluorescein isothiocyanate-conjugated mouse anti-human CD4 antibodies (BD Biosciences; cat. no. 555346), PerCP-Cy ${ }^{\mathrm{TM}}$ 5.5-conjugated mouse anti-human CD25 antibodies (BD Biosciences; cat. no. 560503) and phycoerythrin-conjugated mouse anti-human glycoprotein A repetitions predominant (GARP; cat. no. 562150) antibodies (5 $\mu \mathrm{l}$; BD Biosciences) at $37^{\circ} \mathrm{C}$ for $30 \mathrm{~min}$. Following antibody incubation, the cells were fixed. The remaining cells were then permeabilized and stained with $5 \mathrm{ml}$ Alexa Fluor ${ }^{\circledR}$ 647-conjugated anti-human IL-17A (BD Biosciences; cat. no. 560437). The cells were fixed in $1 \%$ formaldehyde (Sigma-Aldrich), and flow cytometric analyses were performed using a FACSCalibur system (BD Biosciences). The resulting data were analyzed using BD FACSDiva software, version 6.1.2 (BD Biosciences).

Enzyme-linked immunosorbent assay (ELISA). Serum concentrations of IL-22, IL-17A, TGF- $\beta 1$ were measured using a human IL-22 ELISA detection kit, human interleukin-17 (IL-17) ELISA detection kit and human TGF- $\beta$ ELISA detection kit (R\&D Systems, Inc., Minneapolis, MN, USA), according to the protocols provided by the manufacturer. All samples were assessed twice in order to avoid sampling error.

Virological and biochemical assessment. The levels of $\mathrm{HBeAg}$, total bilirubin, ALT, prothrombin time (PT) and prothrombin activity were measured using commercially available kits (Abbott Ireland Diagnostics Ltd., Sligo, Ireland; Roche Diagnostics, Indianapolis, IN, USA; Siemens Healthcare Diagnostics Inc., Newark, USA) in the clinical laboratory of the First Affiliated Hospital of Chongqing Medical University (Chongqing, China). Serum HBV DNA levels were measured using the Hepatitis B Viral DNA Quantitative Fluorescence Diagnostic kit (Shengxiang Inc., Hunan, China). The HBV DNA detection limit was $500 \mathrm{IU} / \mathrm{ml}$. The cycling steps were as follows: $95^{\circ} \mathrm{C}$ for $2 \mathrm{sec} ; 94^{\circ} \mathrm{C}$ for $5 \mathrm{sec} 57^{\circ} \mathrm{C}$ for $30 \mathrm{sec} 45$ times. The expression levels were quantified using a standard curve.

Statistical analysis. All data were analyzed using SPSS 19 software (IBM SPSS, Armonk, NY, USA). Numerical data are expressed as the mean \pm standard error of the mean. Comparison between two groups was performed using two sample Student's t-test. Rates between the groups were compared using a two-sample $\chi^{2}$ test. Comparison between various individuals was performed using a Mann-Whitney U test. Multiple comparisons of different groups were performed using a Kruskal-Wallis H non-parametric test. Correlation 
Table I. Clinical data of the enrolled subjects in the four patient groups.

\begin{tabular}{lcccc}
\hline Factor & $\begin{array}{c}\text { Healthy } \\
\text { control }\end{array}$ & $\begin{array}{c}\text { Chronic active } \\
\text { without cirrhosis }\end{array}$ & $\begin{array}{c}\text { HBV-associated } \\
\text { cirrhosis }\end{array}$ & $\begin{array}{c}\text { Liver } \\
\text { failure }\end{array}$ \\
\hline Cases (n) & 20 & 40 & 27 & 20 \\
Age (years) & $36.40 \pm 5.62$ & $34.61 \pm 11.89$ & $40.06 \pm 16.37$ & $15 / 12$ \\
Gender (M/F) & $6 / 14$ & $26 / 14$ & 11 & 8 \\
HBeAg positive & 0 & 21 & $83.65 \pm 138.92$ & $325.15 \pm 372.49$ \\
ALT (U/l) & - & $462.65 \pm 490.89$ & $73.80 \pm 21.97$ & $39.30 \pm 11.21$ \\
PTA (\%) & - & $90.35 \pm 19.59$ & $4.06 \pm 2.16$ & $6.30 \pm 1.49$ \\
$\log _{10}$ HBV DNA & 0 & $5.00 \pm 1.79$ & & 8.27 \\
\hline
\end{tabular}

Normal range of ALT, 13-69 U/l; Normal range of PTA, 75-135\%. Data for age, ALT, PTA and $\log _{10}$ HBV DNA are expressed as the mean \pm standard error of the mean. M, male; F, female; ALT, alanine aminotransferase; PTA; prothrombin activity; HBV, hepatitis B virus

Table II. nTreg and Th17 cell proportions in the patient groups.

\begin{tabular}{|c|c|c|c|c|}
\hline Cell proportion & Healthy control & CAWC & Cirrhosis & Liver failure \\
\hline nTreg/CD4 ${ }^{+} \mathrm{T}$ & $3.76 \pm 1.40$ & $9.40 \pm 5.81^{\mathrm{b}}$ & $6.61 \pm 3.77$ & $6.26 \pm 3.64$ \\
\hline Th17/CD4+ & $3.26 \pm 2.20$ & $6.41 \pm 2.83^{\mathrm{a}}$ & $5.80 \pm 2.76^{\mathrm{a}}$ & $9.04 \pm 4.94^{\mathrm{b}}$ \\
\hline
\end{tabular}

Data are expressed as the mean \pm standard error of the mean. nTreg, natural regulatory $\mathrm{T}$ cell; Th17, T helper 17; CD, cluster determinant; CAWC, chronic active without cirrhosis. ${ }^{\mathrm{a}} \mathrm{P}<0.05,{ }^{\mathrm{b}} \mathrm{P}<0.001$, compared with the healthy control group.

analysis was evaluated using Spearman's rank correlation test. Two-sided $\mathrm{P}<0.05$ was considered to indicate a statistically significant difference.

\section{Results}

Increased frequencies of circulating Th17 cells correlate with the severity of liver inflammation and fibrosis. The present study characterized $\mathrm{CD} 4^{+} \mathrm{IL}-17^{+}$cells as Th17 cells, and compared the proportions of peripheral Th17 cells among the four groups. There were significantly higher frequencies of circulating Th17 cells in patients with $\mathrm{CHB}$, cirrhosis and liver failure, compared with levels in the normal controls, with values of $6.41 \pm 2.83,5.8 \pm 2.76$ and $9.04 \pm 4.94 \%$, respectively, compared with $3.26 \pm 2.20 \%$ in the control $(\mathrm{P}=0.02,0.029$ and 0.000 , respectively; Fig. 1A-E). The Th17 frequency was highest in the patients in liver failure, which was significantly different, compared with those in the patients with CAWC and cirrhosis $(\mathrm{P}=0.026$ and 0.015 , respectively; Fig. $1 \mathrm{~F}$ and Table II).

Distribution of nTreg cell subset populations. The present study characterized $\mathrm{CD}^{+}{ }^{+} \mathrm{CD} 25^{+} \mathrm{GARP}{ }^{+}$as nTreg cells . There were significantly higher frequencies of circulating nTreg cells in the patients with $\mathrm{CHB}$, compared with the normal controls $(9.4 \pm 5.81$ vs. $3.76 \pm 1.4 \% ; \mathrm{P}<0.001$; Fig. 2A-E). No significant differences in nTreg cell frequencies were observed between the patients with cirrhosis or the patients with liver failure and the normal controls $(6.61 \pm 3.77$ and $6.26 \pm 3.64$, respectively, vs. $3.76 \pm 1.4 \%$ in the control; $\mathrm{P}=0.066$ and $\mathrm{P}=0.144$, respectively).
Serum levels of cytokines in the peripheral blood. In the patients with CAWC, cirrhosis and liver failure, the serum levels of IL-17 were significantly higher, compared with those in the normal controls, with values of $104 \pm 23.8,94 \pm 43.17$ and $165 \pm 36.19 \mathrm{pg} / \mathrm{ml}$, respectively, vs. $72.09 \pm 11.16 \mathrm{pg} / \mathrm{ml}$ in the control ( $\mathrm{P}<0.05$ for all; Fig. 3A). The serum levels of IL-17 were higher, compared with the levels in the patients with CAWC and cirrhosis, in the patients with liver failure. No significant difference in serum levels of IL-17 were observed between the patients with CAWC and the patients with cirrhosis.

In the patients with CAWC, cirrhosis and liver failure, serum levels of IL-22 were significantly higher than in the normal controls $(65.32 \pm 34.12,56.47 \pm 53.06$ and $80.03 \pm 18.40 \mathrm{pg} / \mathrm{ml}$, respectively, vs. $45.09 \pm 34.57 \mathrm{pg} / \mathrm{ml}$ in the control; $\mathrm{P}<0.05$; Fig. 3B). However, no significant differences were observed among the three groups.

In the patients with CAWC, cirrhosis and liver failure, serum levels of TGF- $\beta$ were higher than in the normal controls $(978.76 \pm 117.21,1,008.88 \pm 57.80$ and $936.54 \pm 64.06 \mathrm{ng} / 1$, respectively, vs. $765.75 \pm 134.05 \mathrm{ng} / \mathrm{l}$ in the control). However, the differences among the four groups were not statistically significant $(\mathrm{P}>0.05)$.

Th17 cell frequency and serum levels of IL-17 correlate positively with ALT and PT, but not HBV DNA. The Th17 frequencies and serum levels of IL-17 were significantly and positively correlated with the levels of ALT (normal range, $0-40 \mathrm{U} / \mathrm{l} ; \mathrm{r}=0.368$ and 0.309 , respectively; $\mathrm{P}=0.011$ and 0.035 , respectively), as shown in Fig $4 \mathrm{~A}$ and $\mathrm{B}$. The serum levels of Th17 and IL-17 were significantly and positively correlated 
A
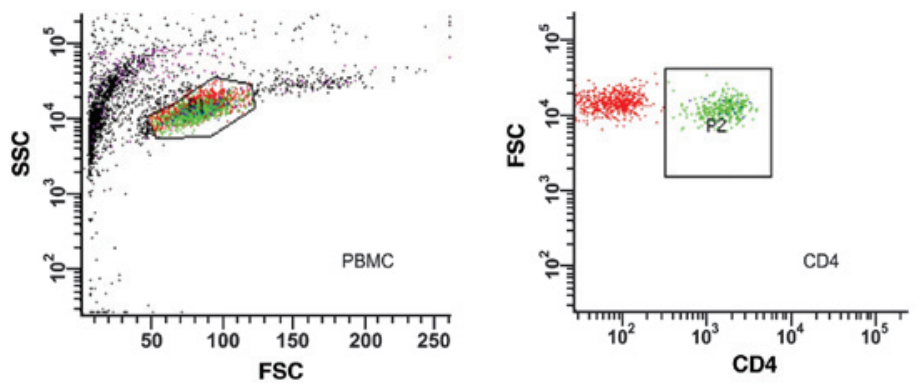

B

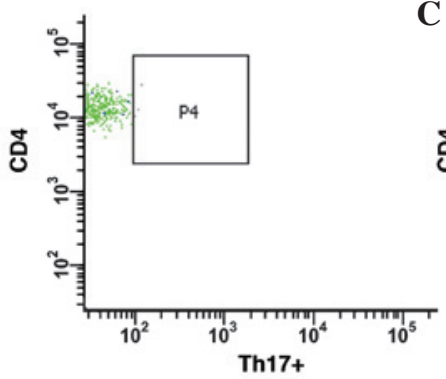

$\mathbf{E}$

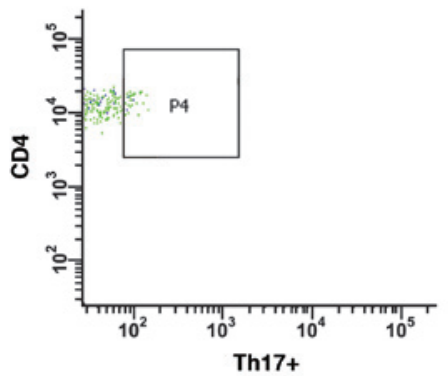

C

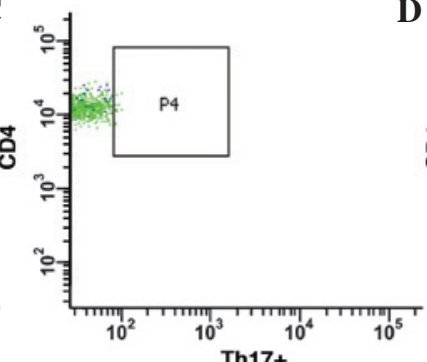

D
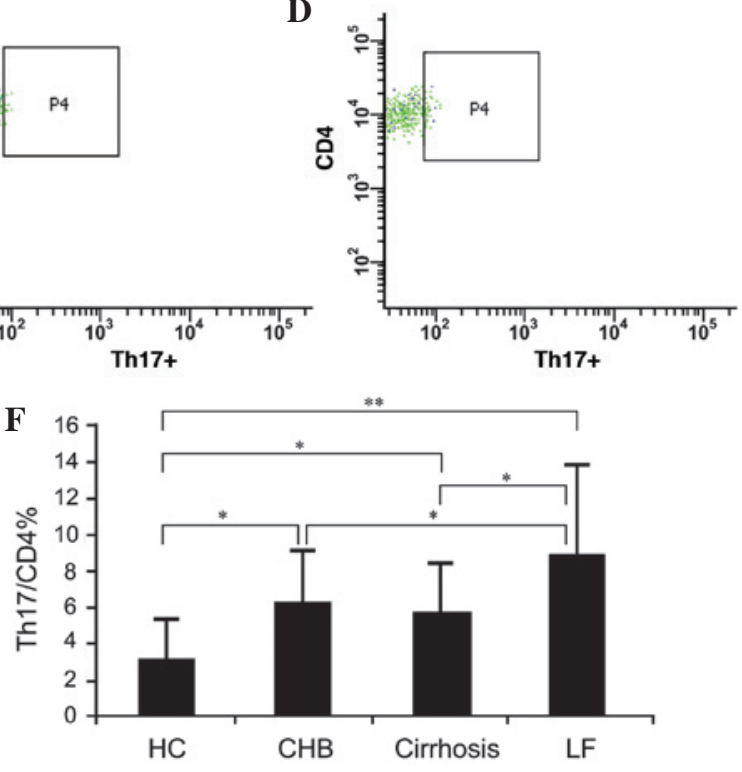

Figure 1. Identification of Th17 cells in the subject groups. (A) Gating of lymphocytes (left, PBMCs; right, CD4). (B) Gating of Th17 cell populations and proportions in healthy controls. (C) Gating of Th17 cell populations and proportions in patients with CAWC. (D) Gating of Th17 cell populations and proportions in patients with cirrhosis. (E) Gating of Th17 cell populations and proportions in patients with liver failure. (F) Proportion of Thl7 cells in the four subject groups. Th17 cells are indicated by the $\mathrm{P} 4$ box. Data are expressed as the mean \pm standard error of the mean $\left({ }^{* *} \mathrm{P}<0.001 ;{ }^{*} \mathrm{P}<0.05\right)$. Th17, T helper $17 ; \mathrm{PBMC}$, peripheral blood mononuclear cell; CD, cluster determinant; HC, healthy control; CAWC, chronic active without cirrhosis; CHB, chronic hepatitis B; LF, liver failure.
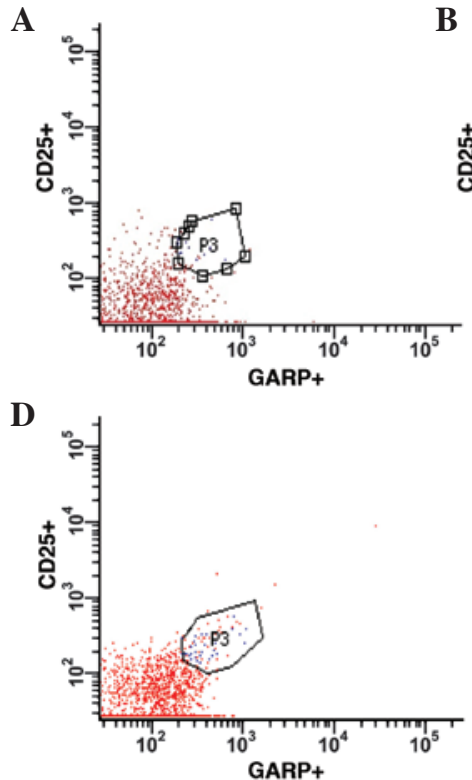
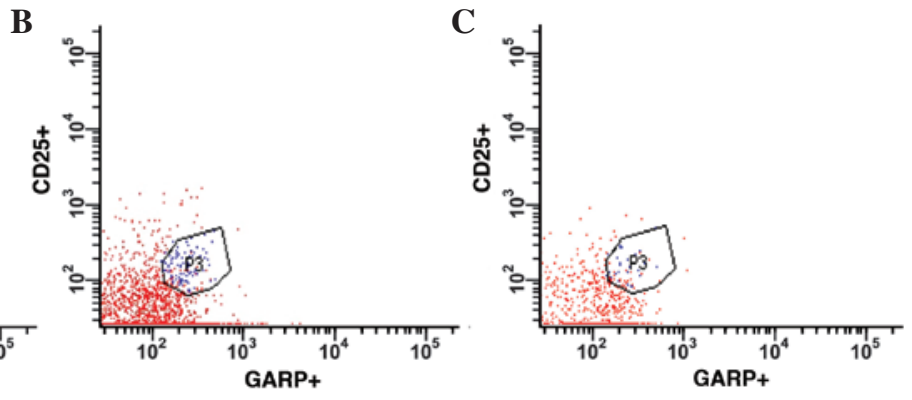

$\mathbf{E}$

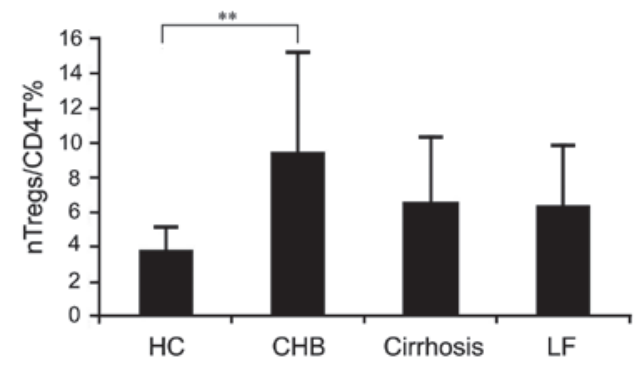

Figure 2. nTreg frequencies. (A) Gating of nTreg cell population and proportions in the HC group (B) Gating of nTreg cell populations and proportion in the CAWC group. (C) Gating of nTreg cell populations and proportions in the cirrhosis group. (D) Gating of nTreg cell populations and proportions in LF group. (E) Proportions of nTreg cells. nTregs are indicated by P3 boundary. Data are expressed as the mean \pm standard error of the mean $\left({ }^{* *} \mathrm{P}<0.001\right)$. nTreg, natural regulatory T cell; PBMC, peripheral blood mononuclear cell; CD, cluster determinant; HC, healthy control; CAWC, chronic active without cirrhosis; CHB, chronic hepatitis B; LF, liver failure. 
A

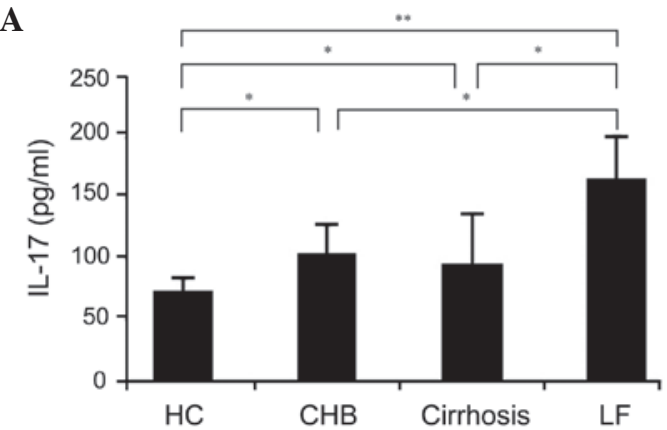

B

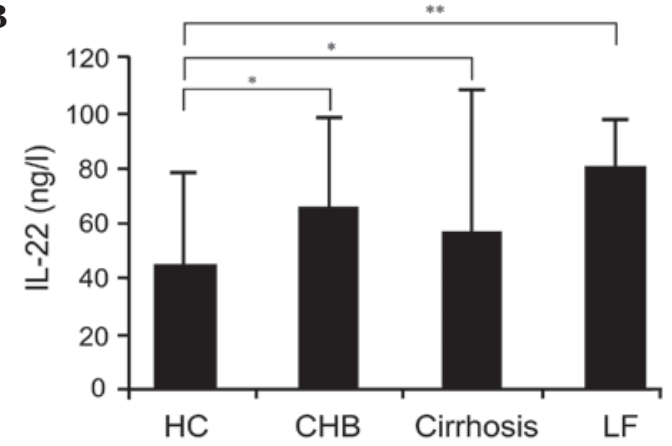

Figure 3. Serum levels of IL-17 and IL-22. (A) Serum levels of IL-17 in the four groups. Data are expressed as the mean \pm standard error of the mean $(* * 20.001$; $\left.{ }^{*} \mathrm{P}<0.05\right)$. (B) Serum IL-22 levels in four groups Data are expressed as the mean \pm standard error of the mean $\left({ }^{* *} \mathrm{P}<0.001\right.$; $\left.{ }^{*} \mathrm{P}<0.05\right)$. IL, interleukin; HC, healthy control; CAWC, chronic active without cirrhosis; CHB, chronic hepatitis B; LF, liver failure.

A

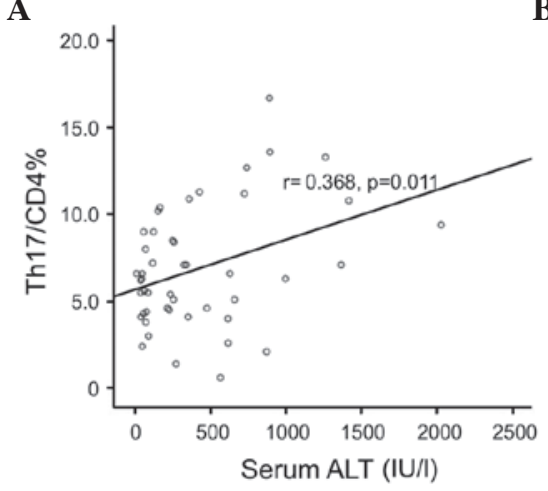

B

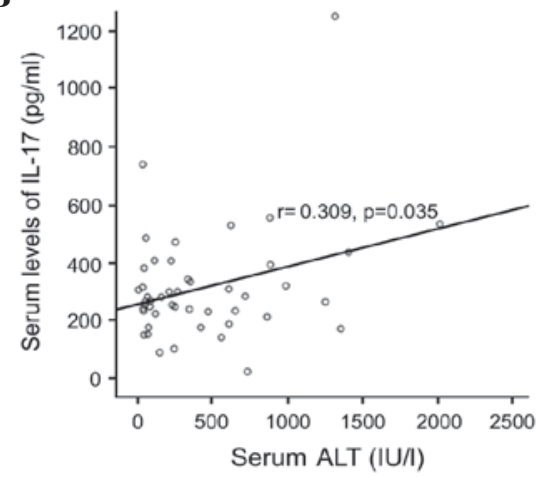

C

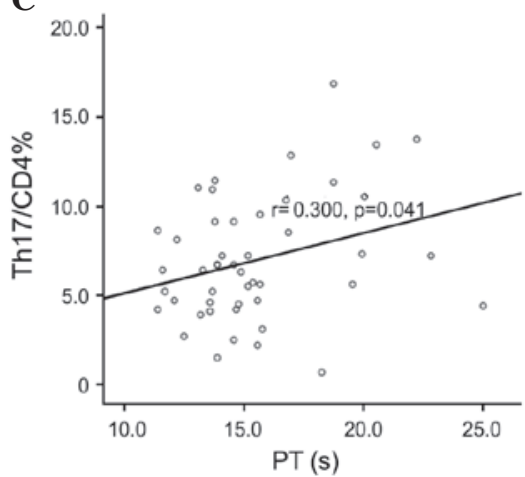

D

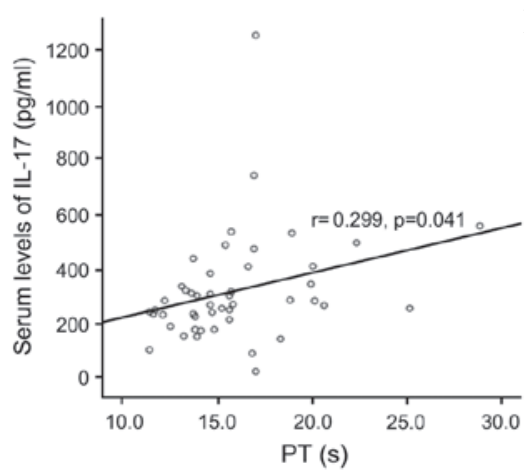

E

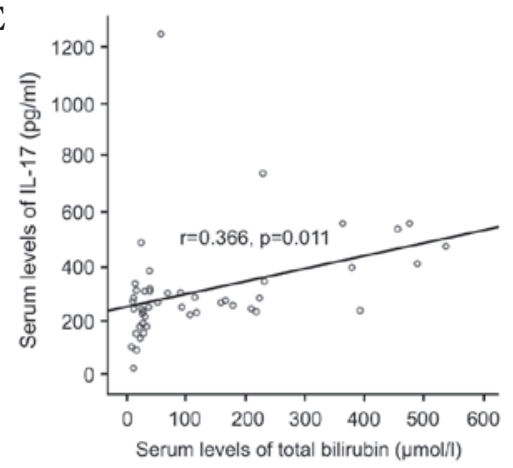

Figure 4. Correlation analysis of various indicators. (A) Peripheral Th17 frequencies and serum levels of ALT. (B) Serum levels of IL-17 and ALT. (C) Peripheral Th17 frequencies and PT. (D) Serum levels of IL-17 and PT. (E) Serum levels of IL-17 and TB. ALT, alanine aminotransferase; IL, interleukin; PT, prothrombin time; TB, total bilirubin; Th17, T helper 17; CD, cluster determinant.

A

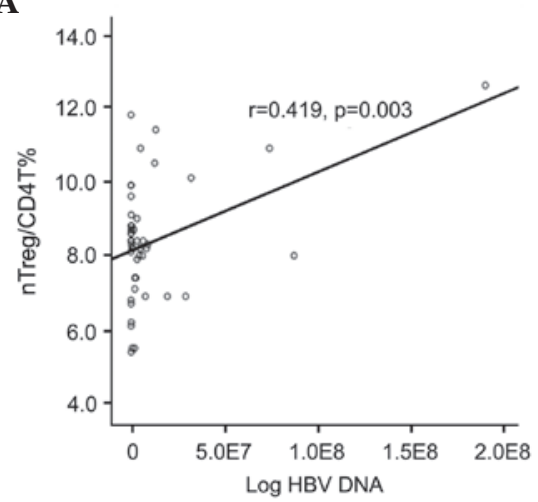

B

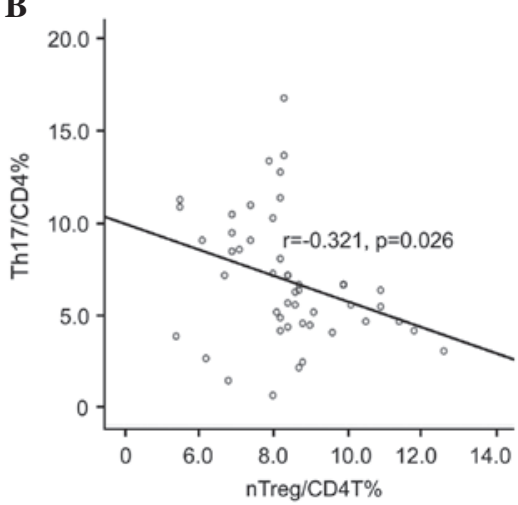

Figure 5. Correlation analyses between nTreg, HBV DNA levels and Th17 frequency. (A) Peripheral nTreg frequencies and HBV DNA levels. (B) Peripheral nTregs and Th17 frequencies. nTreg, natural regulatory T cell; Th17, T helper 17; CD, cluster determinant; HBV, hepatitis B virus. 
with PT (normal range, 11-14.5 sec; $\mathrm{r}=0.300$ and 0.299 , respectively; $\mathrm{P}=0.041$ and 0.041 , respectively), as shown in Fig. 4C and D.

The serum levels of IL-17 levels were significantly positively correlated with the total bilirubin levels $(r=0.366$; $\mathrm{P}=0.011$; Fig. 4E). The Th17 frequency and serum levels of IL-17 were not correlated with HBV DNA levels. These data suggested that peripheral Th17 cell frequencies and serum levels of IL-17 were closely associated with liver injury, as indicated by serum ALT levels and prothrombin time, in the patients with $\mathrm{HBV}$ infection.

nTreg cell frequencies are positively correlated with $H B V$ $D N A$, but not with $A L T$ or $P T$, and are negatively correlated with Th17 cell frequencies. The present study analyzed the correlation between nTreg frequency and clinical data. The nTreg frequencies were significantly and positively correlated with plasma HBV DNA load ( $\mathrm{r}=0.419 ; \mathrm{P}=0.003$; Fig. 5A), but not with the levels of ALT or the PT ( $>>0.05)$.

Further analysis of nTreg frequencies with Th17 frequencies showed that nTreg was negatively correlated with Th17 frequency ( $r=-0.321 ; P=0.026$; Fig. 5B).

\section{Discussion}

There has been a focus of attention on the significance of the Treg/Th17 balance in the progression of CHB. Th17 and Treg cells share reciprocal developmental pathways of cell differentiation (28). The differentiation of Treg cells from naive T cells is dependent on a critical differentiation factor, TGF- $\beta$ (29). The differentiation of pathogenic Th17 cells from naive T cells is induced by IL- 6 and TGF- $\beta$, whereas the differentiation of Treg cells can be completely inhibited by the induction of IL-6 during inflammation (30-32). Not only do Th17 cells and Treg cells share the same origin, but they are also mutually antagonistic in function. A balance between Th17 and Treg cells, which mediates immune tolerance is crucial for immune homeostasis (33).

The balance of Th17 and Treg cells is closely associated with the development of several diseases, including viral infections and autoimmune diseases (34-36). However, little is known regarding the balance of Th17 and Treg cells in the progression of CHB. The present study was designed to further ascertain whether circulating Th17 cells and nTreg cells frequency correlate with the severity of liver injury and fibrosis in the progression of CHB.

A subset of T cells are described as Th17 due to the fact that an IL-12 family cytokine, IL-23, induces these cell to secrete IL-17 $(33,37)$. It has been shown that serum levels of IL-17 and Th17 cells are increased in patients with chronic hepatitis $C$ virus $(38,39)$. However, the mechanism by which Th17 cells induce liver damage in patients with CHB remains to be elucidated. As one of the important pro-inflammatory cytokines, IL-17 can recruit neutrophils, which can induce liver injury (10). In addition, IL-17 can activate mDCs and monocytes, which produce more proinflammatory cytokines in a dose-dependent manner. In the present study, it was found that the Th17 frequencies in the peripheral blood of patients with liver failure were markedly higher, compared with those of patients with CAWC and cirrhosis. The present study provided the first evidence, to the best of our knowledge, that Th17 cell-mediated inflammation is associated with the stages of progression of CHB. Th17 cell frequencies may assist in predicting the severity of liver damage and fibrosis, and Th17 cells may exert their immune effect via IL-17 in the peripheral blood. Further investigation is required to confirm this possibility.

Wang et al (40) were the first to report on the association between GARP and Treg cells. GARP is an orphan Toll-like receptor, composed of leucine-rich repeats. The study demonstrated that GARP was selectively expressed only in activated human nTreg and nTreg cell clones, but not in activated effector $\mathrm{T}$ cells, confirming GARP as a nTreg marker. Therefore, the present study selected GARP, rather than Foxp3, as a $\mathrm{CD}^{+}{ }^{+} \mathrm{CD} 25^{+}$Treg-specific marker. The results of the present study demonstrated that nTreg frequencies in the peripheral blood of patients with CAWC were markedly higher, compared with those in patients with cirrhosis and liver failure, which was consistent with the results of previous studies (11,41-43) and further supports the involvement of Treg cells in the pathogenesis of CAWC. In the presence of cirrhosis and liver failure, the immune tolerance status may change, enhancing HBV clearance.

To further assess the association between the Th17 and Treg cells, the present study analyzed the Treg and Th17 cell correlation, and found that nTreg cell frequencies were negatively correlated with those of Th17 cells. Specifically, the decrease in peripheral nTreg cells were accompanied by an increase in Th17 cells. These data further support the possibility that Treg/Th17 imbalance may be involved in the progression of HBV infection. However, only peripheral blood samples were examined in the present study. Examination of the distribution of Th17 and nTregs cells in the liver of patients with HBV infections may provide additional confirmatory evidence, and are planned in the future.

In conclusion, the findings of the present study demonstrated that pro-inflammatory Th17 cell frequencies are associated with various stages of liver injury during the progression of HBV between simple active hepatitis and liver failure. nTreg cell-mediated immune tolerance was associated with levels of HBV DNA replication. This characterization of the Treg/Th17 balance in the progression of CHB extends current understanding of the immunopathogenesis of CHB, and supports future investigations on pro-inflammatory and anti-inflammatory pathways.

\section{Acknowledgements}

The present study was supported by grants from the Natural Science Foundation of Chongqing City (grant no. cstc2012jjA10052) and the National Natural Science Foundation of China (grant no. 81271838). The authors would like to thank all the participants involved.

\section{References}

1. Ganem D and Prince AM: Hepatitis B virus infection-natural history and clinical consequences. New Engl J Med 350: 1118-1129, 2004.

2. Hernandez-Gea V and Friedman SL: Pathogenesis of liver fibrosis. Annu Rev Pathol 6: 425-456, 2011. 
3. Friedman SL: Evolving challenges in hepatic fibrosis. Nat Rev Gastroenterol Hepatol 7: 425-436, 2010.

4. Wang FS and Zhang Z: Host immunity influences disease progression and antiviral efficacy in humans infected with hepatitis B virus. Expert Rev Gastroenterol Hepatol 3: 499-512, 2009.

5. Dancygier H and Schirmacher P: Immune mediated liver injury. In: Clinical Hepatology. Dancygier H (ed). Springer, Berlin, Germany, pp191-196, 2010.

6. Jung MC and Pape GR: Immunology of hepatitis B infection. Lancet Infect Dis 2: 43-50, 2002.

7. Wang FS: Clinical immune characterization of hepatitis B virus infection and implications for immune intervention: Progress and challenges. Hepatol Res 37 (Suppl 3): S339-S346, 2007.

8. Harrington LE, Hatton RD, Mangan PR, Turner H, Murphy KM and Weaver CT: Interleukin 17-producing CD4+ effector T cells develop via a lineage distinct from the T helper type 1 and 2 lineages. Nat Immunol 6: 1123-1132, 2005.

9. Shi M, Wei J, Dong J, Meng W, Ma J, Wang T, Wang N and Wang Y: Function of interleukin-17 and -35 in the blood of patients with hepatitis B-related liver cirrhosis. Mol Med Rep 11: 121-126, 2015

10. Jaeschke H and Hasegawa T: Role of neutrophils in acute inflammatory liver injury. Liver Int 26: 912-919, 2006.

11. Zhang JY, Zhang Z, Lin F, Zou ZS, Xu RN, Jin L, Fu JL, Shi F, Shi M, Wang HF and Wang FS: Interleukin-17-producing CD4(+) $\mathrm{T}$ cells increase with severity of liver damage in patients with chronic hepatitis B. Hepatology 51: 81-91, 2010.

12. Zhang Z, Zou ZS, Fu JL, Cai L, Jin L, Liu YJ and Wang FS Severe dendritic cell perturbation is actively involved in the pathogenesis of acute-on-chronic hepatitis B liver failure. J Hepatol 49: 396-406, 2008.

13. Szabo G, Mandrekar P and Dolganiuc A: Innate immune response and hepatic inflammation. Semin Liver Dis 27: 339-350, 2007.

14. Ge J, Wang K, Meng QH, Qi ZX, Meng FL and Fan YC: Implication of Th17 and Th1 cells in patients with chronic active hepatitis B. J Clin Immunol 30: 60-67, 2010.

15. Zhao RR, Yang XF, Dong J, Zhao YY, Wei X, Huang CX, Lian JQ and Zhang Y: Toll-like receptor 2 promotes T helper 17 cells response in hepatitis B virus infection. Int J Clin Exp Med 8: 7315-7323, 2015.

16. Li X, Liu X, Tian L, Chen Y. Cytokine-mediated immunopathogenesis of hepatitis B virus infections. Clin Rev Allergy Immunol: 1-14, epub 2014.

17. Kondo Y, Ueno Y and Shimosegawa T: Immunopathogenesis of hepatitis B persistent infection: Implications for immunotherapeutic strategies. Clin J Gastroenterol 2: 71-79, 2009.

18. Kondo Y, Ueno Y, Kobayashi K, Kakazu E, Shiina M, Inoue J, Tamai K, Wakui Y, Tanaka Y, Ninomiya M, et al: Hepatitis $B$ virus replication could enhance regulatory $\mathrm{T}$ cell activity by producing soluble heat shock protein 60 from hepatocytes. J Infect Dis 202: 202-213, 2010.

19. Yuan Q, Hong S, Shi B, Kers J, Li Z, Pei X, Xu L, Wei X and Cai M: CD4(+)CD25(-)Nrp1(+) T cells synergize with rapamycin to prevent murine cardiac allorejection in immunocompetent recipients. PLoS One 8: e61151, 2013.

20. Voelk1 S, Gary R and Mackensen A: Characterization of the immunoregulatory function of human TCR- $\alpha \beta+$ CD4- CD8double-negative T cells. Eur J Immunol 41: 739-748, 2011.

21. Wang BL, Su H, Chen Y, Wang J and Xu GL: A role for trichosanthin in the expansion of CD4CD25 regulatory T cells. Scand J Immunol 71: 258-266, 2015.

22. Lambotin M, Raghuraman S, Stoll-Keller F, Baumert TF and Barth H: A look behind closed doors: Interaction of persistent viruses with dendritic cells. Nat Rev Microbiol 8: 350-360, 2010

23. Xie Q, Shen HC, Jia NN, Wang H, Lin LY, An BY, Gui HL, Guo SM, Cai W, Yu H, et al: Patients with chronic hepatitis B infection display deficiency of plasmacytoid dendritic cells with reduced expression of TLR9. Microbes Infect 11: 515-523, 2009.

24. Carotenuto P, Artsen A, Niesters HG, Osterhaus AD and Pontesilli O: In vitro use of autologous dendritic cells improves detection of $\mathrm{T}$ cell responses to hepatitis B virus (HBV) antigens. J Med Virol 81: 332-339, 2009.
25. Sakaguchi S, Yamaguchi T, Nomura T and Ono M: Regulatory T cells and immune tolerance. Cell 133: 775-787, 2008.

26. Thimme R, Wieland S, Steiger C, Ghrayeb J, Reimann KA, Purcell RH and Chisari FV: CD8(+) T cells mediate viral clearance and disease pathogenesis during acute hepatitis B virus infection. J Virol 77: 68-76, 2003.

27. Pawlotsky JM: EASL Clinical Practice Guidelines. J Hepatol 50: 243, 2009.

28. Bettelli E, Korn T, Oukka M and Kuchroo VK: Induction and effector functions of T(H)17 cells. Nature 453: 1051-1057, 2008.

29. Zhou L, Lopes JE, Chong MM, Ivanov II, Min R, Victora GD, Shen Y, Du J, Rubtsov YP, Rudensky AY, et al: TGF- $\beta$-induced Foxp3 inhibits $\mathrm{T}(\mathrm{H}) 17$ cell differentiation by antagonizing RORgammat function. Nature 453: 236-240, 2008

30. Bettelli E, Carrier Y, Gao W, Korn T, Strom TB, Oukka M, Weiner HL and Kuchroo VK: Reciprocal developmental pathways for the generation of pathogenic effector TH17 and regulatory T cells. Nature 441: 235-238, 2006.

31. Veldhoen M, Hocking RJ, Atkins CJ, Locksley RM and Stockinger B: TGFbeta in the context of an inflammatory cytokine milieu supports de novo differentiation of IL-17-producing T cells. Immunity 24: 179-189, 2006.

32. Ando DG, Clayton J, Kono D, Urban JL and Sercarz EE: Encephalitogenic T cells in the B10. PL model of experimental allergic encephalomyelitis (EAE) are of the Th-1 lymphokine subtype. Cell Immunol 124: 132-143, 1989.

33. Park H, Li Z, Yang XO, Chang SH, Nurieva R, Wang YH, Wang Y, Hood L, Zhu Z, Tian Q and Dong C: A distinct lineage of $\mathrm{CD} 4 \mathrm{~T}$ cells regulates tissue inflammation by producing interleukin 17. Nat Immunol 6: 1133-1141, 2005.

34. Bouchliou I, Miltiades P, Nakou E, Spanoudakis E, Goutzouvelidis A, Vakalopoulou S, Garypidou V, Kotoula V, Bourikas G, Tsatalas C and Kotsianidis I: Th17 and Foxp3(+) $T$ regulatory cell dynamics and distribution in myelodysplastic syndromes. Clin Immunol 139: 350-359, 2011.

35. Maek-A-Nantawat W, Buranapraditkun S, Klaewsongkram J and Ruxrungthum K: Increased interleukin-17 production both in helper T cell subset Th17 and CD4-negative T cells in human immunodeficiency virus infection. Viral Immunol 20: 66-75, 2007.

36. Acosta-Rodriguez EV, Rivino L, Geginat J, Jarrossay D, Gattorno M, Lanzavecchia A, Sallusto F and Napolitani G: Surface phenotype and antigenic specificity of human interleukin 17-producing T helper memory cells. Nat Immunol 8: 639-646, 2007.

37. Harrington LE, Hatton RD, Mangan PR, Turner H, Murphy TL, Murphy KM and Weaver CT: Interleukin 17-producing CD4+ effector $\mathrm{T}$ cells develop via a lineage distinct from the $\mathrm{T}$ helper type 1 and 2 lineages. Nat Immunol 6: 1123-1132, 2005.

38. Lemmers A, Moreno C, Gustot T, Maréchal R, Degré D, Demetter P, de Nadai P, Geerts A, Quertinmont E, Vercruysse $\mathrm{V}$, et al: The interleukin-17 pathway is involved in human alcoholic liver disease. Hepatology 49: 646-657, 2009.

39. Harada K, Shimoda S, Sato Y, Isse K, Ikeda H and Nakanuma Y: Periductal interleukin-17 production in association with biliary innate immunity contributes to the pathogenesis of cholangiopathy in primary biliary cirrhosis. Clin Exp Immunol 157: 261-270, 2009

40. Wang R, Kozhaya L, Mercer F, Khaitan A, Fujii H and Unutmaz D: Expression of GARP selectively identifies activated human FOXP3+ regulatory T cells. Proc Natl Acad Sci U S A 106: 13439-13444, 2009.

41. Peng G, Li S, Wu W, Sun Z, Chen Y and Chen Z: Circulating CD4+ CD25+ regulatory $T$ cells correlate with chronic hepatitis B infection. Immunology 123: 57-65, 2008.

42. Niu Y, Liu H, Yin D, Yi R, Chen T, Xue H, Zhang S, Lin S and Zhao Y: The balance between intrahepatic IL-17(+) T cells and Foxp3(+) regulatory $\mathrm{T}$ cells plays an important role in HBV-related end-stage liver disease. BMC Immunol 12: 47, 2011.

43. Zhang JY, Song CH, Shi F, Zhang Z, Fu JL and Wang FS: Decreased ratio of Treg cells to Th17 cells correlates with HBV DNA suppression in chronic hepatitis B patients undergoing entecavir treatment. PLoS One 5: e13869, 2010. 